\title{
Longitudinal study on clinical and microbial analysis of periodontal status in pregnancy
}

Fernanda Campos MACHADO(a) Dionéia Evangelista CESAR(b) Ana Carolina Morais APOLÔNIO(c) Luiz Claudio RIBEIRO(d) Rosangela Almeida RIBEIRO(e)

(a) Centro Universitário Estácio Juiz de Fora, School of Dentistry, Juiz de Fora, MG, Brazil.

(b) Universidade Federal de Juiz de Fora - UFJF, Biological Sciences Institute, Department of Ecology, Juiz de Fora, MG, Brazil.

(c) Universidade Federal de Juiz de Fora - UFJF, Biological Sciences Institute, Department of Parasitology, Microbiology and Immunology, Juiz de Fora, MG, Brazil.

(d) Universidade Federal de Juiz de Fora UFJF, Department of Statistics, Juiz de Fora, MG, Brazil.

(e) Universidade Federal de Juiz de Fora UFJF, School of Dentistry, Department of Social and Child Dentistry, Juiz de Fora, MG, Brazil.

Declaration of Interests: The authors certify that they have no commercial or associative interest that represents a conflict of interest in connection with the manuscript.

\section{Corresponding Author:}

Fernanda Campos Machado

E-mail: fercampo@terra.com.br

DOI: 10.1590/1807-3107BOR-2016.vol30.0087

Submitted: Oct 14, 2015

Accepted for publication: Apr 25, 2016

Last revision: May 24, 2016
Abstract: This study was aimed to provide a longitudinal overview of the subgingival bacterial microbiome using fluorescence in situ hybridization (FISH) technique, in women in the second trimester of pregnancy (between 14 and 24 weeks), and $48 \mathrm{~h}$ and 8 weeks postpartum. Of 31 women evaluated during pregnancy, 24 returned for the 48-h and 18 for their 8-week exams postpartum. Probing depth (PD), bleeding on probing, clinical attachment level, and presence of calculus were recorded. Subgingival plaque samples were collected, and FISH was used to identify the numbers of eight periodontal pathogens. Friedman test was used to compare differences between follow-up examinations, followed by a multiple comparison test for a post hoc pairwise comparison. Clinically, a significantly greater number of teeth with $\mathrm{PD}=4-5 \mathrm{~mm}$ were found during pregnancy than on postpartum examinations. Microbial analysis showed a statistically significant decrease in cell count over the study period for Prevotella nigrescens. P. intermedia, Campylobacter rectus, and Porphyromonas gingivalis also decrease, although not significantly, and Aggregatibacter actinomycetemcomitans increased. No significant changes were found for Fusobacterium nucleatum, Treponema denticola, or Tannerella forsythia. Our data demonstrate a change in the subgingival microbiota during pregnancy, at least for $P$. nigrescens.

Keywords: Pregnancy; Microbiology; Biofilms; In Situ Hybridization, Fluorescence.

\section{Introduction}

The association between adverse pregnancy outcomes and periodontopathogenic microorganisms has been suggested by several authors, but as yet, there is no consensus in the literature. Although changes in periodontal status during pregnancy have been reported, the exact sequence of events from periodontal health to disease in pregnant women remains unknown. ${ }^{1,2,3,4,5,6}$ Several factors have been investigated during research on periodontal disease in pregnancy, including hormone levels,,$^{78}$ virulence factors of microorganisms, ${ }^{9,10}$ changes in immunologic responses, ${ }^{5,11}$ and microbiota. $12,13,14,15,16,17,18$

Various types of analysis and models have proven helpful in understanding the multi-factorial causes of periodontal disease. ${ }^{7,19,20,21}$ Of these, bacterial challenge studies have provided a valuable contribution to understanding the complex pathogenesis of periodontal disease. ${ }^{22}$ 
Most studies on periodontal microbiota have used cultures, ${ }^{12,15,19}$ conventional PCR, ${ }^{22}$ real-time $\mathrm{PCR}^{14}$ checkerboard DNA-DNA hybridization, ${ }^{9,16,23}$ and, most recently, DNA sequencing technologies. ${ }^{24}$ However, because these approaches are based on various parameters and have differing sensitivities, it is very difficult to compare the results to clearly elucidate microbial community structure.

With fluorescence in situ hybridization (FISH), it is possible to compare microbial community structure, i.e., the number of cells of each species individually and the proportion of these cells in the total. ${ }^{13,25,26}$

The complex pathogenesis of periodontal disease implies the involvement of a susceptible host and a bacterial challenge. ${ }^{23}$ To qualitatively and quantitatively understand the bacterial microbial community, focusing on individual cell counts during and after pregnancy might be helpful in choosing appropriate management of oral conditions in these patients. ${ }^{13}$ Thus, we designed this study to longitudinally evaluate the subgingival bacterial microbiome using FISH in pregnant woman before and after delivery. We studied the main species involved in periodontitis and their association with the patients' oral clinical status.

The null hypothesis is that there are no changes in clinical and microbial parameters during pregnancy and postpartum.

\section{Methodology}

This longitudinal study was approved by the Ethics Committee in Human Research of the Federal University of Juiz de Fora (UFJF), MG, Brazil (protocol number 262/2008).

\section{Study population}

Expectant mothers were recruited between June 2010 and July 2011 during routine prenatal health visits to a public reference hospital in Juiz de Fora, MG, Brazil.

Initially, 158 women receiving prenatal care were screened for inclusion. Women aged 24 to 32 years old, with a singleton pregnancy, in the second trimester (between 14 and 24 weeks, confirmed by ultrasound), in good general health, and with a minimum of 20 permanent teeth were invited to participate. Exclusion criteria included chronic disease (i.e., diabetes, hypertension, epilepsy, cardiac disease, lung disease, renal disease, or a positive test for human immunodeficiency virus), smoking, alcohol dependency, use of systemic antibiotics, and/or psychotropic or anticonvulsant medication in the preceding 3 months, a requirement for prophylactic antibiotics for periodontal examination, current orthodontic treatment, or a history of professional tooth-cleaning in the preceding 6 months. ${ }^{13}$

A total of 31 women fulfilled the eligibility criteria and signed informed consent. The women were also examined at the beginning of the study and at $48 \mathrm{~h}$ and 8 weeks postpartum.

Information about age, marital status, medical history, education, and economic level was assessed by interview.

\section{Periodontal examination}

The clinical periodontal examination was performed as in our previous study, ${ }^{13}$ and included the following parameters; bleeding on probing (BOP), presence of calculus (PC), probing depth (PD), and clinical attachment level (CAL). All teeth were examined with the exception of the third molars; six sites per tooth were examined with a North Carolina periodontal probe (PCP-UNC 15, Hu-Friedy Manufacturing Inc., Chicago, USA), and the heights of BOP, PC, PD, and CAL were registered as scores for each tooth. This periodontal examination was conducted by a single, trained, and calibrated dentist (FCM), and results were recorded on standardized forms by trained assistants. Cohen's kappa coefficients for intra-examiner agreement were 0.86 for PD and 0.90 for CAL.

Periodontitis was defined as the presence of four or more teeth with one or more sites of $\mathrm{PD} \geq 4 \mathrm{~mm}$ and $\mathrm{CAL} \geq 3 \mathrm{~mm}$ at the same site. ${ }^{27}$

\section{Microbiological analysis}

Plaque sampling was conducted as described by Machado et al. ${ }^{13}$ The supragingival biofilm was removed with sterile gauze, and subbgingival biofilm samples were collected from the mesial surfaces of two opposite and contralateral first molars (or, if missing, the next most posterior tooth) using a sterile Gracey curette (Hu-Friedy Manufacturing Inc. Chicago, USA). The biofilm samples were transferred into a $1.5 \mathrm{ml}$ 
screw-cap microtube and immediately transported on dry ice to the laboratory. The microtubes were weighed before and immediately after sampling to allow quantitative analysis. The samples were fixed and stored in paraformaldehyde solution, $2 \%$ final concentration. The material was kept in a freezer at $20^{\circ} \mathrm{C}$ until used for microbiological analysis.

FISH was carried out to identify and enumerate the periodontal pathogens in the subgingival biofilm of the women at each visit. Eight species-specific $16 \mathrm{~S}$ rRNA oligonucleotide probes (Operon Technologies Inc., Alameda, USA), labeled with Cy3 fluorescent dye, were used to identify the following microorganisms; Aggregatibacter actinomycetemcomitans, Tannerella forsythia, Campylobacter rectus, Porphyromonas gingivalis, Treponema denticola, Fusobacterium nucleatum, Prevotella intermedia, and P. nigrescens. A negative control probe with a sequence that should not bind to any prokaryote rRNA was used. ${ }^{24}$ Further details of these probes were described in our previous study. ${ }^{13}$

The total number of bacterial cells and cells from each species determined by FISH were assessed according to the methods described by Machado et al. ${ }^{13}$ The percentage of each species in relation to the total bacterial cell count was calculated. Results were expressed in cells/g.

\section{Statistical analysis}

Statistical analysis was performed using the Statistical Package for Social Science (SPSS) 14.0 (SPSS
Inc., Chicago, USA) and R software (library "agricolae"). Nominal data were described by relative and/or absolute frequencies. Numerical data were described by mean, standard deviation, and minimum and maximum values. Statistical differences were determined by a non-parametric Friedman test, followed by a multiple comparison test for a post hoc pairwise postpartum. Statistical significance was defined as $p<0.05$.

\section{Results}

The mean age of the 31 women initially enrolled was 26.7 years ( $\mathrm{SD} \pm 2.5$ ), and the mean gestational age at first evaluation was 19.0 weeks $(\mathrm{SD} \pm 3.3)$. All children were born at term (mean, $39.0 \pm 1.47$ weeks; range, 37-41 weeks) with normal weight (mean, $3.283 \pm 0.467 \mathrm{~kg}$; range, $2.525-4.220 \mathrm{~kg}$ ).

Of the 31 women evaluated during the second trimester, 24 returned for the 48 -h examination and 18 for the 8-week examination postpartum; however, only the 18 women who participated in all three examinations were analyzed. Reasons for dropout included withdrawal for personal reasons (loss of interest or lack of time, $n=7)$, unable to be located $(n=3)$, change of city $(n=2)$, and development of hypertension $(n=1)$.

\section{Clinical parameters}

Data regarding clinical periodontal condition at the three examinations are shown in Table 1 . The average of the number of teeth was $27.0 \pm 1.3$ (range, 24-28 teeth).

Table 1. Clinical parameters during the second trimester of pregnancy and $48 \mathrm{~h}$ and 8 weeks postpartum $(\mathrm{n}=18)$.

\begin{tabular}{|c|c|c|c|c|c|}
\hline Variable (\%) & Parameters & $2^{\text {nd }}$ trimester & $48 \mathrm{~h}$ postpartum & 8 weeks postpartum & Friedman test \\
\hline \multirow{2}{*}{ Teeth with BOP } & Mean \pm SD & $44.5 \pm 25.2$ & $36.8 \pm 22.8$ & $40.6 \pm 22.3$ & \multirow{2}{*}{$p=0.17$} \\
\hline & Range & $7.7-100$ & $3.0-76.0$ & $11.1-92.9$ & \\
\hline \multirow{2}{*}{ Teeth with PC } & Mean \pm SD & $8.4 \pm 11.0$ & $9.3 \pm 11.5$ & $7.9 \pm 10.9$ & \multirow{2}{*}{$P=0.09$} \\
\hline & Range & $0-36.0$ & $0-36.0$ & 0-35.7 & \\
\hline \multirow{2}{*}{ Teeth with PD $=4-5 \mathrm{~mm}$} & Mean \pm SD & $4.7 \pm 14.3$ & $1.2 \pm 4.0$ & $0.3 \pm 1.6$ & \multirow{2}{*}{$p=0.02$} \\
\hline & Range & $0-64.0$ & $0-18.5$ & $0-7.4$ & \\
\hline \multirow{2}{*}{ Teeth with PD $\geq 6 \mathrm{~mm}$} & Mean \pm SD & $0.2 \pm 0.9$ & - & - & \multirow{2}{*}{$p=0.37$} \\
\hline & Range & $0-4$ & - & - & \\
\hline \multirow{2}{*}{ Teeth with $C A L=3-5 \mathrm{~mm}$} & Mean \pm SD & $2.0 \pm 8.8$ & $2.1 \pm 10.0$ & $2.2 \pm 10.2$ & \multirow{2}{*}{$p=0.13$} \\
\hline & Range & $0-48.1$ & $0-48.1$ & $0-48.1$ & \\
\hline
\end{tabular}

* $\mathrm{BOP}=$ bleeding on probe; $\mathrm{PC}=$ presence of calculus; $\mathrm{PD}=$ probing depth; $\mathrm{CAL}=$ clinical attachment level; $\mathrm{SD}=$ standard deviation; $\mathrm{n}=$ number 
There was no statistical difference between the three examinations with respect to $\mathrm{BOP}, \mathrm{PC}, \mathrm{PD} \geq 6 \mathrm{~mm}$, or $\mathrm{CAL}=3-5 \mathrm{~mm}$. There were fewer teeth with $\mathrm{PD}=4-5 \mathrm{~mm}$ at the postpartum examinations, a difference that was significant according to the Friedman test $(p=0.02)$. This result was not confirmed in the comparison of two examinations by a multiple comparison test.

\section{Microbial parameters}

Table 2 presents the values for the total bacterial counts and the eight periodontal pathogens detected in the women's subgingival biofilm.

Statistical analysis failed to demonstrate significant differences in total bacterial counts during pregnancy and postpartum.

A significant reduction was seen, however for $P$. nigrescens when all three time points were compared ( $p=0.01$, Friedman test). The subsequent multiple comparison test demonstrated significant differences in the counts of this periodontal pathogen when time points were compared in pairs; second trimester versus 8 weeks postpartum ( $p=0.002)$, and 48 h versus 8 weeks postpartum $(p=0.037)$.

Figure 1 shows the percentage of each species in relation to total bacterial cell counts during the second trimester, at $48 \mathrm{~h}$ and 8 weeks postpartum.

\section{Discussion}

The results of this study performed in women with normal, uncomplicated pregnancies provide new information about subgingival microbial changes during and after pregnancy. As demonstrated by FISH, there may be distinctions among certain microbial types in periodontal areas during and after pregnancy.

Considering all bacteria evaluated in the study, high variability was observed during and after pregnancy (Table2). Although there were changes in the percentage of each species in relation to the total bacterial cell counts at each point in the study (Figure), with decreases seen in P. intermedia, F. nucleatum, P. gingivalis, T. denticola, C. rectus and an increase in $A$. actinomycetemcomitans, these differences were not statistically significant.

Table 2. Mean, standard deviation (SD), and minimum and maximum values of total bacterial counts and of each periodontal pathogen (cells $\times 10^{7} / \mathrm{g}$ ) during the second trimester of pregnancy and $48 \mathrm{~h}$ and 8 weeks postpartum $(\mathrm{n}=18)$.

\begin{tabular}{|c|c|c|c|c|c|}
\hline Bacterial counts (cells $\times 10^{7} / \mathrm{g}$ ) & Parameters & $2^{\text {nd }}$ trimester & $48 \mathrm{~h}$ postpartum & 8 weeks postpartum & Friedman test \\
\hline \multirow{2}{*}{ Total bacterial count } & Mean \pm SD & $513.8 \pm 20.2$ & $521.1 \pm 228.9$ & $520.5 \pm 168.8$ & \multirow{2}{*}{$p=0.16$} \\
\hline & Range & 179.6-982.3 & $226.4-1161.9$ & $227.8-805.2$ & \\
\hline \multirow{2}{*}{ A. actinomycetemcomitans } & Mean \pm SD & $8.9 \pm 11.2$ & $7.9 \pm 10.7$ & $11.2 \pm 10.6$ & \multirow{2}{*}{$p=0.93$} \\
\hline & Range & $0-56.4$ & $0-53.6$ & $2.0-42.2$ & \\
\hline \multirow{2}{*}{ T. forsythia } & Mean \pm SD & $21.5 \pm 17.7$ & $19.9 \pm 14.1$ & $20.1 \pm 14.1$ & \multirow{2}{*}{$p=0.41$} \\
\hline & Range & $2.5-74.9$ & $4.9-51.6$ & $6.7-50.4$ & \\
\hline \multirow{2}{*}{ C. rectus } & Mean \pm SD & $12.8 \pm 12.9$ & $10.5 \pm 7.8$ & $9.4 \pm 7.9$ & \multirow{2}{*}{$p=0.32$} \\
\hline & Range & $0-43.9$ & 1.2-31.2 & $0.8-31.6$ & \\
\hline \multirow{2}{*}{$P$ gingivalis } & Mean \pm SD & $19.6 \pm 32.8$ & $17.9 \pm 24.8$ & $11.6 \pm 6.1$ & \multirow{2}{*}{$p=0.24$} \\
\hline & Range & $0-181.0$ & $2.1-130.0$ & $2.1-22.9$ & \\
\hline \multirow{2}{*}{ T. denticola } & Mean \pm SD & $14.2 \pm 12.7$ & $14.0 \pm 12.2$ & $12.1 \pm 10.0$ & \multirow{2}{*}{$p=0.24$} \\
\hline & Range & $0-59.2$ & $0.8-59.2$ & $0-39.7$ & \\
\hline \multirow{2}{*}{ F. nucleatum } & Mean \pm SD & $26.4 \pm 25.6$ & $25.1 \pm 21.3$ & $21.5 \pm 16.1$ & \multirow{2}{*}{$p=0.52$} \\
\hline & Range & $0-133.0$ & 1.9-91.3 & $4.4-52.6$ & \\
\hline \multirow{2}{*}{ P. intermedia } & Mean \pm SD & $37.0 \pm 87.1$ & $34.0 \pm 65.6$ & $14.9 \pm 14.1$ & \multirow{2}{*}{$p=0.13$} \\
\hline & Range & $0-474.0$ & $0.8-312.5$ & $3.6-50.2$ & \\
\hline \multirow{2}{*}{ P. nigrenscens } & Mean \pm SD & $19.6 \pm 18.3$ & $17.9 \pm 15.6$ & $17.0 \pm 15.0$ & \multirow{2}{*}{$p=0.01$} \\
\hline & Range & $0-57.8$ & $0-54.8$ & $2.4-53.4$ & \\
\hline
\end{tabular}




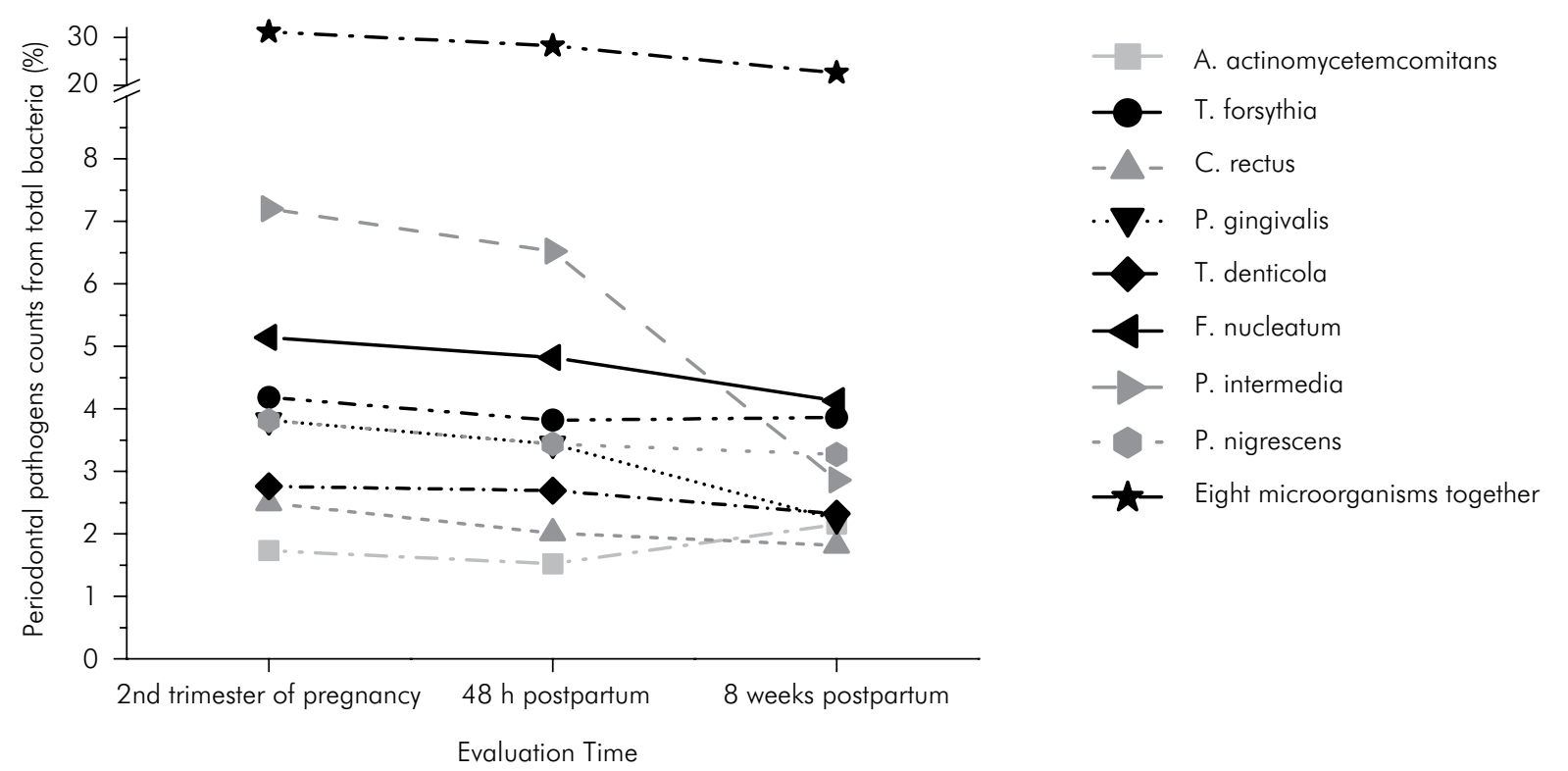

Figure. Counts of periodontal pathogens in percentage (\%) when analyzed with $100 \%$ of total bacteria found in each sample point.

The only significant change we found was a decrease in P. nigrescens over the course of the study; the count for this organism was significantly lower at $48 \mathrm{~h}$ and 8 weeks postpartum than during the second trimester. Although differences for other microorganisms were not statistically significant, the proportion of each is interesting and is thus worth discussing.

The role of $P$. nigrescens in periodontal disease is controversial. Some authors have suggested it is frequently detected at healthy sites, ${ }^{17,28}$ whereas others consider it to be related to periodontal disease and/or endodontic infections. ${ }^{29,30}$ The first report of $P$. nigrescens in pregnant women was in 2009, with a high percentage of $P$. nigrescens observed in this group. ${ }^{22}$ The data obtained in our study suggest that $P$. nigrescens is somehow related to pregnancy status as it decreased significantly postpartum. However, it is noteworthy that other studies to report changes in the composition of periodontopathogenic microbiota during pregnancy did not assess $P$. nigrescens as since the 1980s, the periodontal pathogen most commonly associated with pregnancy has been $P$. intermedia. ${ }^{12,19,31}$ In fact, we found a higher percentage of $P$. intermedia (7.2\%) during pregnancy than $P$. nigrescens (3.81\%). Contrary to our findings, in their longitudinal study, Adriaens et $a .^{16}$ found no differences in P. intermedia during pregnancy and postpartum. However, they used checkerboard DNA-DNA hybridization rather than FISH. In a comparison of pregnant and non-pregnant women, ${ }^{13}$ higher counts of $P$. intermedia were also observed during pregnancy, although the difference was not statistically significant. Raber-Durlacher et al. ${ }^{21}$ observed an increase in the percentage of $P$. intermedia in the subgingival biofilm during experimental induction of gingivitis in pregnant women, yet no increase was observed during the same procedure performed in the postpartum period.

It has been suggested that $P$. intermedia and P. nigrescens are strongly associated with periodontal disease and can contribute to increased incidence of disease as they comprise the orange group described by Socranscy ${ }^{23}$ required for isolating the red group associated with severe forms of periodontitis. C. rectus is also part of the orange group, and may be associated with an increased risk of premature births and low birth weight. ${ }^{2,3,4,5}$ We detected higher counts of $C$. rectus during pregnancy $(2.5 \%)$ than at 8 weeks postpartum (1.8\%). Consistent with our findings, Yokoyama et al. ${ }^{18}$ detected higher counts of $C$. rectus in the saliva of pregnant women by quantitative real-time PCR, suggested that this may contribute to periodontal disease progression, and may be associated with increased salivary estradiol concentrations during pregnancy. 
As well as $C$. rectus, $P$. gingivalis also decreased somewhat at 8 weeks postpartum (2.23\%) compared with the second trimester of pregnancy (3.81\%). Studies have shown a high prevalence of $P$. gingivalis and $P$. intermedia during the second trimester of pregnancy due to high concentrations of progesterone and/or estradiol, which contribute to bacterial growth. ${ }^{12,20}$ Our results corroborate these earlier findings as these species were more frequent during pregnancy at 8 weeks postpartum. Based on accumulated evidence, an increased detection of $P$. gingivalis during pregnancy and a decrease postpartum were expected.

We observed an increase in the bacterium A. actinomycetemcomitans over the study period, in contrast to the decrease seen in most of the other microorganisms studied. Indeed, other authors ${ }^{14}$ have found a higher proportion of this microorganism during pregnancy and have suggested that its participation in periodontal changes associated with pregnancy is important. However, earlier works differ from ours because they have quantified this bacterium in terms of the number of copies of DNA amplified by specific probes rather than by directly counting the number of bacterial cells.

The proportions of F. nucelatum, T. denticola, and T. forsythia did not differ significantly over the study period.

The eight selected microorganisms in our study are all considered in the literature to be periodontopathogenic bacteria. ${ }^{16}$ With the exception of $A$. actinomycetemcomitans, they comprise the red and orange complexes, ${ }^{22}$ associated with the various forms of periodontal disease. However, in light of the more than 800 species estimated to be components of the indigenous oral microbiota, our eight surveyed species represent an average of $27.34 \%$ of the total cells detected in this study. Indeed, their proportion of the total tends to decrease after delivery. Thus, considering the well-accepted theory that specific dental plaques are responsible for the development of periodontal disease (gingivitis and periodontitis), our data are interesting from the point-of-view of microbial ecology. Even given good periodontal health, these eight periodontal pathogens are part of the indigenous oral microbiota, albeit in reduced amounts. ${ }^{23}$ Although in the healthy state, there is a balance between microbiota virulence factors and host defense factors, if this equilibrium is disrupted by microbial or host factors, including hormonal changes during pregnancy, these specific pathogens can increase in number and lead to the development of periodontal disease (gingivitis and periodontitis). Although these aspects were not evaluated in this study, this theory is accepted by other authors ${ }^{13,15}$ who have suggested that $P$. gingivalis, $P$. nigrescens, $C$. rectus, and $A$. actinomycetemcomitans can be implicated as risk factors for adverse pregnancy outcomes, including prematurity and low birth weight.

Inconsistent results in the literature in relation to the oral bacteria associated with the onset of periodontal diseases during pregnancy can be explained by the different methodologies used in each study. ${ }^{13,4,32}$ Although the presence of periodontal bacteria can be demonstrated using various methods, including DNA-DNA hybridization or oral microbiota culture, ${ }^{12,15,19}$ our use of FISH allows for direct counts of the cell numbers of each microorganism in relation to the total cell count.

Among the limitations of this study was the high dropout rate, especially at the 8 week postpartum examination, which could have introduced bias into the results. This dropout rate is perhaps explainable by the fact that pregnant, or breastfeeding, women may have a number of reasons that hinder attendance to dental appointments. ${ }^{33}$ Another weakness of the study is the small sample size, perhaps not large enough to detect differences in bacterial cell counts between the three examinations. However, this study is important because it shows the ability of FISH to quantify bacteria by counting cells, thereby yielding information on the specific proportions of species in the microbiota, unobtainable by other previously used techniques in oral microbial research.

Thus, new detection techniques, including FISH, open the door on a new microbiological era in which microorganisms can be detected directly as individual cells in patient samples. Rather than depending on indirect data from cultures or DNA extraction, FISH is a reliable, fast, and efficient quantitative method. This new technique has great potential for future studies as it has proven effective for the identification, visualization, and quantification of several species of periodontal bacteria. 
This study demonstrates, using FISH, the presence of certain microorganisms in periodontal areas during uncomplicated pregnancies and deliveries, which tend to decrease in number postpartum.

\section{Conclusions}

This study confirms the hypothesis that there is a change in the subgingival microbiota, at least for $P$. nigrescens, between pregnancy and the postpartum period.

\section{Acknowledgments}

This study was supported by research grants from CAPES, Brasilia, Brazil, as well as by grants from the Postgraduate Program in Health of UFJF, Brazil.

\section{References}

1. Barak S, Oettinger-Barak O, Machtei EE, Sprecher H, Ohel G. Evidence of periopathogenic microorganisms in placentas of women with preeclampsia. J Periodontol. 2007;78(4):670-6. doi:10.1902/jop.2007.060362

2. Mitchell-Lewis D, Engebretson SP, Chen J, Lamster IB, Papapanou PN. Periodontal infections and pre-term birth: early findings from a cohort of young minority women in New York. Eur J Oral Sci. 2001;109(1):34-9. doi:10.1034/j.1600-0722.2001.00966.x

3. Madianos PN, Lieff S, Murtha AP, Boggess KA, Auten RL, Beck JD et al. Maternal periodontitis and prematurity. Part II: maternal infection and fetal exposure. Ann Periodontol. 2001;6(1):175-82. doi:10.1902/annals.2001.6.1.175

4. Buduneli N, Baylas H, Buduneli E, Türkoğlu O, Köse T, Dahlen G. Periodontal infections and pre-term low birth weight: a case-control study. J Clin Periodontol. 2005;32(2):174-81. doi:10.1111/j.1600-051X.2005.00670.x

5. Lin D, Moss K, Beck JD, Hefti A, Offenbacher S. Persistently high levels of periodontal pathogens associated with preterm pregnancy outcome. J Periodontol. 2007;78(5):833-41. doi:10.1902/jop.2007.060201

6. Corbella S, Taschieri S, Del Fabbro M, Francetti L, Weinstein R, Ferrazzi E. Adverse pregnancy outcomes and periodontitis: a systematic review and meta-analysis exploring potential association. Quintessence Int. 2016;47(3):193-204. doi:10.3290/j.qi.a34980

7. Miyazaki H, Yamashita Y, Shirahama R, Goto-Kimura K, Shimada N, Sogame A et al. Periodontal condition of pregnant women assessed by CPITN. J Clin Periodontol. 1991;18(10):751-4. doi:10.1111/j.1600-051X.1991.tb00067.x

8. Gürsoy M, Gürsoy UK, Sorsa T, Pajukanta R, Könönen E. High salivary estrogen and risk of developing pregnancy gingivitis. J Periodontol. 2013;84(9):1281-9. doi:10.1902/jop.2012.120512

9. Shah HN, Gharbia SE. Biochemical and chemical studies on strains designated Prevotella intermedia and proposal of a new pigmented species, Prevotella nigrescens sp. nov. Int J Syst Bacteriol. 1992;42(4):542-6. doi:10.1099/00207713-42-4-542
10. Gillespie MJ, Smutko J, Haraszthy GG, Zambon JJ. Isolation and partial characterization of the Campylobacter rectus cytotoxin. Microb Pathog. 1993;14(3):203-15. doi:10.1006/mpat.1993.1020

11. Markou E, Eleana B, Lazaros T, Antonios K. The influence of sex steroid hormones on gingiva of women. Open Dent J. 2009;3(1):114-9. doi:10.2174/1874210600903010114

12. Kornman KS, Loesche WJ. The subgingival microbial flora during pregnancy. J Periodontal Res. 1980;15(2):111-22. doi:10.1111/j.1600-0765.1980.tb00265.x

13. Machado FC, Cesar DE, Assis AV, Diniz CG, Ribeiro RA. Detection and enumeration of periodontopathogenic bacteria in subgingival biofilm of pregnant women. Braz Oral Res. 2012;26(5):443-9. doi:10.1590/S1806-83242012000500011

14. Borgo PV, Rodrigues VA, Feitosa AC, Xavier KC, Avila-Campos MJ. Association between periodontal condition and subgingival microbiota in women during pregnancy: a longitudinal study. J Appl Oral Sci. 2014;22(6):528-33. doi:10.1590/1678-775720140164

15. Emmatty R, Mathew JJ, Kuruvilla J. Comparative evaluation of subgingival plaque microflora in pregnant and non-pregnant women: A clinical and microbiologic study. J Indian Soc Periodontol. 2013;17(1):47-51. doi:10.4103/0972-124X.107474

16. Adriaens LM, Alessandri R, Spörri S, Lang NP, Persson GR. Does pregnancy have an impact on the subgingival microbiota? J Periodontol. 2009;80(1):72-81. doi:10.1902/jop.2009.080012

17. Gmür R, Guggenheim B. Interdental supragingival plaque: a natural habitat of Actinobacillus actinomycetemcomitans, Bacteroides forsythus, Campylobacter rectus, and Prevotella nigrescens. J Dent Res. 1994;73(8):1421-8. doi:10.1177/00220345940730080501

18. Yokoyama M, Hinode D, Yoshioka M, Fukui M, Tanabe S, Grenier D et al. Relationship between Campylobacter rectus and periodontal status during pregnancy. Oral Microbiol Immunol. 2008;23(1):55-9. doi:10.1111/j.1399-302X.2007.00391.x 
19. Carrillo-de-Albornoz A, Figuero E, Herrera D,

Bascones-Martínez A. Gingival changes during pregnancy: II. Influence of hormonal variations on the subgingival biofilm. J Clin Periodontol. 2010;37(3):230-40. doi:10.1111/j.1600-051X.2009.01514.x

20. Jonsson R, Howland BE, Bowden GH. Relationships between periodontal health, salivary steroids, and Bacteroides intermedius in males, pregnant and non-pregnant women. J Dent Res. 1988;67(8):1062-9. doi:10.1177/00220345880670080101

21. Raber-Durlacher JE, Steenbergen TJ, Van der Velden U, Graaff J, Abraham-Inpijn L. Experimental gingivitis during pregnancy and post-partum: clinical, endocrinological, and microbiological aspects. J Clin Periodontol. 1994;21(8):549-58. doi:10.1111/j.1600-051X.1994.tb01172.x

22. Gürsoy M, Haraldsson G, Hyvönen M, Sorsa T, Pajukanta R, Könönen E. Does the frequency of Prevotella intermedia increase during pregnancy? Oral Microbiol Immunol. 2009;24(4):299-303. doi:10.1111/j.1399-302X.2009.00509.x

23. Socransky SS, Haffajee AD, Cugini MA, Smith C, Kent RL Jr. Microbial complexes in subgingival plaque. J Clin Periodontol. 1998;25(2):134-44. doi:10.1111/j.1600-051X.1998.tb02419.x

24. DiGiulio DB, Callahan BJ, McMurdie PJ, Costello EK, Lyell DJ, Robaczewska A et al. Temporal and spatial variation of the human microbiota during pregnancy. Proc Natl Acad Sci USA. 2015;112(35):11060-5. doi:10.1073/pnas.1502875112

25. Cottrell MT, Kirchman DL. Community composition of marine bacterioplankton determined by $16 \mathrm{~S}$ rRNA gene clone libraries and fluorescence in situ hybridization. Appl Environ Microbiol. 2000;66(12):5116-22. doi:10.1128/AEM.66.12.5116-5122.2000
26. Moter A, Göbel UB. Fluorescence in situ hybridization (FISH) for direct visualization of microorganisms.

J Microbiol Methods. 2000;41(2):85-112. doi:10.1016/S0167-7012(00)00152-4

27. López NJ, Smith PC, Gutierrez J. Higher risk of preterm birth and low birth weight in women with periodontal disease. J Dent Res. 2002;81(1):58-63. doi:10.1177/154405910208100113

28. Mättö J, Saarela M, Troil-Lindén B, Könönen E, Jousimies-Somer $\mathrm{H}$, Torkko $\mathrm{H}$ et al. Distribution and genetic analysis of oral Prevotella intermedia and Prevotella nigrescens. Oral Microbiol Immunol. 1996;11(2):96-102. doi:10.1111/j.1399-302X.1996.tb00342.x

29. Kuhnert P, Frey J, Lang NP, Mayfield L. Phylogenetic analysis of Prevotella nigrescens, Prevotella intermedia and Porphyromonas gingivalis clinical strains reveals a clear species clustering. Int J Syst Evol Microbiol. 2002;52(4):1391-5. doi:10.1099/00207713-52-4-1391

30. Pearce MA, Devine DA, Dixon RA, Steenbergen TJ. Genetic heterogeneity in Prevotella intermedia, Prevotella nigrescens, Prevotella corporis and related species isolated from oral and nonoral sites. Oral Microbiol Immunol. 2000;15(2):89-95. doi:10.1034/j.1399-302x.2000.150204.x

31. Jensen J, Liljemark W, Bloomquist C.The effect of female sex hormones on subgingival plaque. J Periodontol. 1981;52(10):599-602. doi:10.1902/jop.1981.52.10.599

32. Gürsoy M, Pajukanta R, Sorsa T, Könönen. Clinical changes in periodontium during pregnancy and post-partum. J Clin Periodontol. 2008;35(7):576-83. doi:10.1111/j.1600-051X.2008.01236.x

33. Moreira CHC, Weidlich P, Fiorini T, Rocha JM, Musskopf ML, Susin C et al. Periodontal treatment outcomes during pregnancy and postpartum. Clin Oral Investig. 2015;19(7):1635-41. doi:10.1007/s00784-014-1386-Z 